\title{
The Impact of Uncertainty Shocks on the Volatility of Commodity Prices
}

\author{
Dimitrios Bakas ${ }^{a, c}$ and Athanasios Triantafyllou ${ }^{b \dagger}$ \\ ${ }^{a}$ Nottingham Business School, Nottingham Trent University, UK \\ ${ }^{b}$ Essex Business School, University of Essex, UK \\ ${ }^{c}$ Rimini Centre for Economic Analysis (RCEA), Canada
}

\begin{abstract}
In this paper, we empirically examine the impact of uncertainty shocks on the volatility of commodity prices. Using several alternative measures of economic uncertainty for the U.S., we estimate their effects on commodity price volatility through VAR analysis. We find that the latent uncertainty shocks have the most significant impact on commodity price volatility when compared to observable measures of economic uncertainty. In specific, our results show that the unobservable economic uncertainty measures of Jurado et al. (2015) have a significant and long-lasting positive effect on the volatility of commodity prices. Our findings indicate that a positive shock in unobservable macroeconomic and financial uncertainty leads to a persistent increase in the volatility of the broad commodity market index and of individual commodity prices, with the macroeconomic effect being more significant. Finally, we show that the impact is stronger in energy commodities compared to agricultural and metals markets.
\end{abstract}

Keywords: Economic Uncertainty, Commodity Prices, Volatility

JEL Classification: C22, E32, G13, O13, Q02

\footnotetext{
${ }^{\dagger}$ Acknowledgments: We would like to thank the Editor, K.G. Koedijk and an anonymous referee for their constructive comments and helpful suggestions. In addition, we would like to thank Robert Ackrill, Christopher Lalley, Piers Thompson, Leighton Vaughan Williams and Christoph Wegener for their valuable comments and suggestions on earlier versions of this work. Finally, we would also like to thank the participants of the 2017 Paris Financial Management Conference (PFMC2017) for their useful comments and suggestions. Any remaining errors are the responsibility of the authors.

Corresponding author: Athanasios Triantafyllou, Essex Business School, University of Essex, Wivenhoe Park, Colchester, C04 3SQ, United Kingdom.

E-mail addresses: dimitrios.bakas@ntu.ac.uk (D. Bakas), a.triantafyllou@essex.ac.uk (A. Triantafyllou).
} 


\section{Introduction}

Uncertainty shocks have a significant negative impact on the macroeconomy (Bloom, 2009; Colombo, 2013; Jurado et al., 2015; Baker et al., 2016; Caldara et al., 2016; Henzel and Rengel, 2017; Meinen and Roehe, 2017). According to these empirical studies, a rise in economic uncertainty, as measured by several alternative proxies proposed in the literature, has a negative effect on aggregate investment, industrial production and the employment rate. Moreover, many recent empirical studies indicate that economic policy uncertainty (EPU henceforth) shocks, in the form suggested by Baker et al. (2016), result in an increase in stock-market turbulence. ${ }^{1}$ While many studies verify this negative impact of uncertainty shocks on the macroeconomy and equity markets, there is limited empirical evidence in the literature regarding the impact of uncertainty shocks on the volatility of commodity prices (Watugala, 2015; Joets et al., 2016; Van Robays, 2016).

In this paper, we extend the literature by examining the effects of economic uncertainty on commodity market volatility. ${ }^{2}$ Using various alternative proxies of economic uncertainty for the U.S. and a realized volatility measure for the broad commodity market index, in addition to a panel of 14 individual energy, agricultural and metal commodities, we estimate the impact of uncertainty shocks on commodity price volatility with VAR analysis. All previous work (Watugala, 2015; Joets et al., 2016; Van Robays, 2016) concentrates only on macroeconomic uncertainty without discriminating between observable and latent uncertainty shocks, and does not provide any evidence on the impact of financial uncertainty. Motivated by these empirical studies, we aim to fill this gap in the literature by examining the distinguished effects of observable and unobservable uncertainty measures on the volatility of commodity prices. In this way, our paper is the first providing a unified and more complete investigation of the impact of observable and latent (macroeconomic and financial) uncertainty shocks on commodity price volatility.

\footnotetext{
${ }^{1}$ For example, Antonakakis et al. (2013), Arouri et al. (2016), Kang and Ratti (2014) and Pastor and Veronesi (2012) show that rising economic policy uncertainty reduces stock-market prices, while Liu and Zhang (2015) and Pastor and Veronesi (2012), among others, find that economic policy uncertainty shocks have a significant positive impact on stock-market volatility. Lastly, Kelly et al. (2016) and Pastor and Veronesi (2013) show that political uncertainty increases significantly the option-implied and the realized volatility in U.S. equity markets.

${ }^{2}$ With the term 'economic uncertainty' we refer to both macroeconomic and financial uncertainty. Later in the paper we describe analytically the definitions of both macroeconomic and financial uncertainty shocks.
} 
We can identify in the literature two structurally different approaches for the measurement of economic uncertainty: observable and unobservable (or latent) uncertainty measures. The observable measures of economic uncertainty are those that can be proxied by the time-series variation of observable economic indicators, such as stock-market volatility (VXO) used in Bloom (2009) or uncertainty about future economic policy, which is based on economic news released in newspaper articles (EPU) (see Baker et al., 2016, for more details on this approach). The unobservable economic uncertainty measures are based on the empirical method of Jurado et al. (2015) (referred hereafter as JLN measures). According to this approach, economic uncertainty cannot be measured by observed fluctuations in various economic indicators because these indicators may fluctuate for several reasons which are not at all related to uncertainty. ${ }^{3}$ Jurado et al. (2015) define and measure economic uncertainty as the volatility of the unforecastable component of a large group of important economic (macroeconomic and financial) indicators. In this paper, we use various alternative proxies for economic uncertainty in order to examine which type of uncertainty shock matters most for commodity investors. Our results reveal that a rising degree of unpredictability over the future state of the macroeconomy as well as of the financial sector (i.e., an increase in the unobservable JLN measures of Jurado et $a l ., 2015)$ is a significant common factor of the contemporaneous rise in the volatility of commodity prices. The economic interpretation of this finding is that rising uncertainty about macroeconomic conditions is translated into rising uncertainty about future aggregate demand and supply, and since commodity prices are mainly driven by aggregate demand and supply conditions, their volatility increases due to these highly uncertain conditions in the macroeconomy. More specifically, our results show that the unobservable (latent) uncertainty JLN measures of Jurado et al. (2015) have a more significant and long-lasting impact on commodity market volatility compared to the observable economic uncertainty measures, such as the EPU index of Baker et al. (2016) and the VXO stock-market index. Therefore, what matters most

\footnotetext{
${ }^{3}$ Jurado et al. (2015) argue that stock-market volatility "can change over time even if there is no change in uncertainty about economic fundamentals, if leverage changes, or if movements in risk aversion or sentiment are important drivers of economic fluctuations. Cross sectional dispersion in the individual stock returns can fluctuate without any change in uncertainty if there is heterogeneity in the loadings of the common risk factors." In addition, Bekaert et al. (2013) provide empirical support to this argument by showing that the time-varying stock-market volatility (as proxied by the VIX index) can be decomposed to investor's risk aversion and to economic uncertainty. Therefore, equity market volatility may change due to changes in risk aversion without any necessary change in economic uncertainty.
} 
for commodity investors, is not the macroeconomic and stock-market fluctuations per se, but the degree of unpredictability over these types of fluctuations. According to our findings, commodity markets are relatively immune to sudden changes in the stock-market and the uncertainty about future economic policy. What is important for investors in commodity markets is their ability to anticipate and foresee the sudden swings and turbulence in the financial sector and the macroeconomy. As long as they achieve this, commodity markets become less volatile and less correlated with macroeconomic fluctuations.

Our econometric analysis reveals that in highly unpredictable periods, commodity market volatility rises. This result sheds some light and provides a pure macroeconomic explanation of the rapid rise in the volatility of commodity prices over the 2006-2008 period. The analysis indicates that the highly unpredictable macroeconomic environment (and not the rising volatility in macroeconomic indicators) is the key determinant of the rising volatility in the commodity markets. Our findings reveal that, the more economic agents are able to predict future macroeconomic fluctuations, the less volatile commodity markets will be.

In more detail, our VAR analysis shows that the unobservable economic uncertainty shocks have a more significant (in terms of magnitude) and long-lasting impact on the volatility of commodity prices compared to observable uncertainty shocks. The estimated Impulse Response Functions (IRFs) show that a $1 \%$ positive shock in the logarithm of the JLN uncertainty index increases the volatility in the commodity price index by $1.1 \%$ in the case of a macroeconomic uncertainty shock, and by $0.6 \%$ in the case of a financial uncertainty shock, with the responses of commodity market volatility remaining positive and statistically significant for almost 15 months after the initial uncertainty shock. On the other hand, the impact of the EPU shocks on commodity market volatility has a much smaller and rather transitory effect on the volatility of commodity prices. Our estimated IRFs indicate that commodity market variance increases by $0.03 \%$ ( 3 basis points) after applying a $1 \%$ EPU shock and the response vanishes 2 months after the initial uncertainty shock. Our results are robust when we use alternative components of the EPU index, for example the EPU news uncertainty, the monetary policy uncertainty and the fiscal policy uncertainty proxy.

Despite the evidence from previous studies that monetary policy shocks have a significant negative impact on commodity prices, and that expansionary monetary 
policy is associated with higher commodity prices (see Frankel and Hardouvelis, 1985; Gordon and Rowenhorst, 2006; Frankel, 2008; Frankel and Rose, 2010; Gilbert, 2010; Anzuini et al., 2013; Frankel, 2013; Gubler and Hertweck, 2013; Hammoudeh et al., 2015), we find that the uncertainty about the future path of monetary policy has a rather transitory and insignificant impact on the volatility of commodity prices. Moreover, when examining the reverse channel of causality, we find that the JLN macroeconomic uncertainty is significantly reduced after the occurrence of commodity volatility shocks. The significant reduction of macroeconomic uncertainty after the realization of large commodity volatility episodes shows that the volatility of commodity prices represents a large fraction of the uncertainty in the macroeconomic environment, and as long as the volatility shock takes place, the future (expected) state of the macroeconomy becomes less 'foggy' as a result.

In addition to measuring the responses of uncertainty shocks on the volatility of the broad commodity futures index, we examine the impact of economic uncertainty on a panel of individual commodities. In the analysis we include the most important (in terms of liquidity of the underlying commodity futures market) commodities for the energy, metals and agricultural commodity classes. Our main results and conclusions remain unaltered when we examine the impact of uncertainty shocks on the monthly realized variance of individual commodity futures prices. More specifically, we find that the volatility of agricultural, energy and metals commodity prices increases significantly after an uncertainty shock. The instant, synchronous and significantly positive jump of the volatility of commodity prices in response to the JLN macroeconomic uncertainty shocks shows that macroeconomic uncertainty is a common (latent) factor behind the time-varying volatility of energy, metals and agricultural commodity markets. Moreover, our empirical analysis shows that the volatility of the energy commodity markets has a more instant and significant response to uncertainty shocks when compared to the volatility responses of the metals and agricultural commodity futures markets. These results are in line with the findings of the relevant literature according to which oil price and uncertainty shocks have a negative impact on the macroeconomy (Ferderer, 1996; Hamilton, 2003; Kilian, 2008; Elder and Serletis, 2010; Rahman and Serletis, 2011; Jo, 2014; Elder, 2018). In addition, we identify a reverse channel of causality, according to which, uncertainty about future economic activity significantly affects the volatility in energy commodity prices. Our work contributes to the relevant literature since we show that 
there is a causal nexus between uncertainty in the macroeconomy and in the oil market. While the empirical studies in the relevant literature show that higher uncertainty in crude oil markets depresses economic activity, our analysis reveals that higher uncertainty in the macroeconomy creates more turbulence in the oil market.

Previous empirical studies exploring the common factors driving volatility in commodity markets do not provide any support for a common macroeconomic factor driving the time-variation in commodity market volatility. ${ }^{4}$ Pindyck and Rotemberg (1990) were among the first to identify the "excess co-movement" of commodity prices. They conclude that this "excess co-movement" is well in excess of anything that can be explained by common macroeconomic factors like inflation, exchange rates or changes in aggregate demand. Our empirical findings provide an explanation for this puzzling phenomenon, since we empirically verify that the JLN macroeconomic uncertainty measure is a common macro factor which drives the time-varying volatility in commodity prices.

The rest of the paper is organized as follows. Section 2 describes the data. Section 3 presents the empirical results, while Section 4 provides various robustness checks. Finally, Section 5 concludes.

\section{Data}

\subsection{Commodity Futures Data}

We use the daily excess returns of the S\&P GSCI indices on commodity futures prices. More specifically, we use the daily excess returns of the broad commodity futures market index as our proxy for the daily price of a basket of commodities. In addition, we obtain the individual daily time series of agricultural, energy and metals commodities of the S\&P GSCI commodity futures indices. Our cross-section of agricultural commodities includes cocoa, corn, cotton, soybeans, sugar and wheat, while the cross-section of energy commodities includes crude oil, heating oil, petroleum and unleaded gasoline, and lastly, the cross-section of metals commodities includes gold, silver, copper and platinum. The commodity futures dataset covers the

\footnotetext{
${ }^{4}$ For example, Batten et al. (2010) show that there are no common macroeconomic factors influencing the dynamics of the monthly volatility series of metals prices. According to their findings the monthly volatility of gold prices is affected by changes in monetary factors, while the same is not true for silver. In further support of these empirical results, Hammoudeh and Yuan (2008) find that while the monetary and oil price shocks reduce the volatility of precious metals (gold and silver), they do not have the same effect for the volatility of copper prices.
} 
period from January 1985 until December 2016. All the S\&P GSCI daily series of commodity futures prices are downloaded from Datastream.

For the computation of the monthly realized variance we follow the empirical approach of Christensen and Prabhala (1998) and Wang et al. (2012) and estimate the realized variance as the monthly variance of the daily returns of commodity futures as follows ${ }^{5}$ :

$$
R V_{t, T}=\frac{1}{T} \sum_{i=1}^{T}\left(\frac{F_{t+i}-F_{t+i-1}}{F_{t+i-1}}-\frac{\overline{F_{t+i}-F_{t+i-1}}}{F_{t+i-1}}\right)^{2},
$$

where $F_{t}$ is the commodity futures price on the trading day $t$ and the time interval $(t, T)$ is the number of trading days during each monthly period. $R V_{t, T}$ is the estimated realized variance for each monthly period. Our monthly estimate of the annualized realized variance $(C O M R V)$ is the monthly variance of the daily returns of commodity prices (for each month), multiplied by 252 (the number of trading days in each calendar year), $C O M R V=R V_{t, T} * 252$.

\subsection{Economic Uncertainty Data}

The unobserved (latent) measures of macroeconomic uncertainty (MU) and financial uncertainty (FU) are based on the JLN approach. ${ }^{6}$ The JLN MU1, MU3 and MU12 uncertainty measures are the macroeconomic uncertainty series which represent the unobservable estimate of macroeconomic uncertainty with 1,3 and 12 month forecasting horizon respectively. The same holds for the JLN FU1, FU3 and FU12 financial uncertainty variables. In the main econometric analysis, we use the 3-month ahead macroeconomic uncertainty (MU3) and financial uncertainty (FU3) measures

\footnotetext{
${ }^{5}$ In financial econometrics literature the realized variance $(R V)$ is usually defined as the best discrete time estimator of the quadratic return variation $(Q V)$ which is equal to the sum of the quadratic realized returns for a given time period (Carr and $\mathrm{Wu}, 2009$ ). This kind of estimation is usually applied when dealing with high-frequency intraday data for which the sum of quadratic returns converges more efficiently to the integrated quadratic return variation process (Barndorff-Nielsen and Sheppard, 2002). In our case, where we deal with daily data, we follow the empirical approach of Wang et al. (2012) by estimating the realized variance as the monthly variance of daily commodity futures returns, as shown in Equation (1).

${ }^{6}$ The measures of Jurado et el. (2015) are downloaded from: https://www.sydneyludvigson.com/dataand-appendixes.
} 
as the benchmark cases. Thus, our MU and FU time series correspond to the MU3 and FU3 uncertainty series of JLN. ${ }^{7}$

Our observable measure of economic uncertainty is based on the approach of Baker et al. (2016), where economic uncertainty is proxied by the uncertainty about economic policy observed in economic related news in newspaper articles. We include the monthly time series for the EPU index by Baker et al. (2016), and its components, containing the fiscal policy uncertainty (EPUFISC), monetary policy uncertainty (EPUMON), as well as the uncertainty measure on news about economic policy (EPUNEWS) and the uncertainty measure on news about financial regulation (FRU). ${ }^{8}$ We additionally include some widely accepted measures of economic uncertainty (see Bloom, 2009), such as the monthly VXO index and the realized variance of the daily returns of the S\&P 500 stock-market index (SP500RV). The daily series of the S\&P 500 index (SP500) and the monthly VXO data are downloaded from Datastream. All the economic uncertainty series have monthly frequency and cover the period from January 1985 until December $2016 .{ }^{9}$

\subsection{Macroeconomic Data}

We obtain monthly time series data for the U.S. industrial production index and employment in the manufacturing sector (MIPI and MEMP). We additionally estimate the slope of the term structure (or term spread) as the difference between the 10-year constant U.S. government bond yield and the 3-month U.S. treasury bill rate (TERM). Lastly, we use the U.S. effective exchange rate $(\mathrm{EXCH})$ and the logarithm of the crude oil price (OILP). All the monthly macroeconomic time-series variables used in our analysis are downloaded from Datastream and cover the period from January 1985 until December 2016.

\section{Empirical Results}

\subsection{Descriptive Statistics and Unit Root Tests}

\footnotetext{
${ }^{7}$ For robustness purposes, we provide additional results using the JNL MU1, MU12 and FU1, FU12 measures of economic uncertainty. The empirical findings using these measures of uncertainty remain unaltered. These additional results can be provided upon request.

8 The measures of Baker et al. (2016) are downloaded from the EPU website at: http://www. policyuncertainty.com.

${ }^{9}$ The realized variance (SP500RV) of the S\&P 500 index has been estimated by applying the same methodology as in Equation (1).
} 
Table 1 presents the descriptive statistics along with the respective unit-root tests of the commodity price volatility, the various uncertainty measures and the financial and macroeconomic control variables which are used in the empirical analysis. ${ }^{10}$

\section{[Insert Table 1 Here]}

From Table 1 we observe that all explanatory variables are stationary (both the $\mathrm{ADF}$ and the PP unit root tests reject the hypothesis of a unit root for all variables). The only exceptions are the log of the manufacturing industrial production index and the $\log$ of the U.S. employment in the manufacturing sector for which we cannot reject the hypothesis of a unit root. Furthermore, the means of the logarithmic uncertainty measures have nearly equal values (for example, the mean value of the $\log$ of the EPU index is 4.639 while the mean of the log of the MU index is 4.356). In contrast, the volatility (i.e., the standard deviation) of the observable economic uncertainty indices like the VXO and the EPU index is nearly three times larger compared with the standard deviation of the unobservable JLN MU index. Figures 1 and 2 below show the contemporaneous time series movements of the realized variance $(\mathrm{COM} R V)$ of the commodity price index and the MU and FU uncertainty series respectively.

\section{[Insert Figure 1 Here]}

[Insert Figure 2 Here]

Figure 1 shows the contemporaneous movements of the JLN MU and the realized variance $(\mathrm{COM} R V)$ in commodity prices. We can observe that rapid rises in MU are followed by volatility spikes in the commodity price index and that the realizations of large shocks in the RV of commodity prices (e.g., the 2008-2009 volatility episode) are followed by a less uncertain (as indicated by a rapid reduction in the MU index) macroeconomic environment. Figure 2 shows the respective

\footnotetext{
${ }^{10}$ The time series variables of unobserved macroeconomic and financial uncertainty (namely the MU and FU variables) have been multiplied with 100 to be comparable with the observable economic uncertainty measures like the EPU level and its components. This transformation is essential to measure and compare the magnitude of the impact between observable (EPU) and unobservable (MU and FU) uncertainty shocks. Using this transformation, the estimated Impulse Response Functions (IRFs) based on the VAR models are of the same magnitude, and thus their impact can be directly comparable.
} 
contemporaneous movements of the JNL FU index and the variance of the commodity price index. The relationship between FU and commodity price RV is similar with that of MU and RV, but we can identify that some spikes in the FU index are not followed by analogous commodity market volatility jumps.

\subsection{The Impact of Uncertainty Shocks on Commodity Price Volatility}

\subsubsection{The Impact of Unobservable Uncertainty Shocks}

In this section we present the results of our multivariate (6-factor) VAR model in which we include the logarithm of the manufacturing industrial production index (MIPI)), the logarithm of the manufacturing employment (MEMP)), the logarithm of the uncertainty index $(\log ($ Uncertainty $)$ - MU, FU or EPU accordingly), the term spread (TERM) (the difference between the 10-year U.S. government bond yield and the 3-month U.S. T-bill rate), the logarithm of the monthly price S\&P500 index (SP500RV) and the realized variance of the daily returns of commodity futures price index (COMRV)) as endogenous variables. ${ }^{11}$ The estimated 6-factor model is inspired by the multivariate VAR models of Bloom (2009) and Baker et al. (2016). ${ }^{12}$

The reduced form VAR model is given in Equation (2) below:

$$
Y_{t}=A_{0}+A_{1} Y_{t-1}+\ldots+A_{k} Y_{t-k}+\varepsilon_{t}
$$

where $A_{0}$ is a vector of constants, $A_{1}$ to $A_{k}$ are matrices of coefficients and $\varepsilon_{t}$ is the vector of disturbances which have serially uncorrelated disturbances, zero mean and a variance-covariance matrix $E\left(\varepsilon_{t}, \varepsilon_{t}^{\prime}\right)=\sigma_{\varepsilon}^{2} I . Y_{t}$ is the vector of endogenous variables. All variables are in monthly frequency and cover the period from January 1985 to December 2016. The ordering in our 6-factor VAR model is as follows:

\footnotetext{
${ }^{11}$ With the term 'uncertainty' we denote all the alternative economic uncertainty indices we employ to measure the impact of the different indicators of economic uncertainty. Economic uncertainty refers both to macroeconomic and financial uncertainty. In our empirical analysis, in the main paper and the online appendix, we use five different indicators of economic uncertainty and four different indicators of financial uncertainty, thus, we estimate a total of nine multivariate VAR models.

12 Since we want to examine the impact of uncertainty shocks on the commodity price volatility, and since the commodity prices are directly linked to the manufacturing production process, we choose to include the manufacturing industrial production and employment (instead of the respective aggregate figures for U.S. industrial production and employment which are being used in the VAR model of Bloom (2009) and Baker et al. (2016)). Another minor difference is that instead of the Federal Funds rate (FFR) and the logarithm of the consumer price index $(\log (\mathrm{CPI}))$, we use the term spread which includes the expectations about the future level of short-term interest rates and inflation. In addition, in our baseline VAR model we exclude the wages and the working hours.
} 


$$
Y_{t}=\left[\operatorname{MIPI}_{t} \operatorname{MEMP}_{t} \mathrm{MU}_{t} \text { TERM }_{t} \mathrm{SP500}_{t} \mathrm{COMRV}_{t}\right]
$$

Following the modeling approach of Bekaert et al. (2013), we choose to place macroeconomic variables first and the financial variables (term spread, stock-market, and commodity market) last in the VAR ordering selection due to more sluggish response of the former compared to the latter ones. We estimate a VAR model with 4 lags ( $k=4$ in Equation (2)). The VAR(4) model is selected based on the Frechet and the Akaike optimal lag-length VAR criteria. ${ }^{13}$ Table 2, reports the Granger causality tests between the alternative proxies of economic uncertainty and the volatility of the commodity price index. The tests are conducted using the baseline 6-factor VAR model given in Equation (3), in order to control for different macroeconomic and financial shocks like the industrial production and the interest rates (term spread) shocks. We estimate a total of nine VAR models by placing the nine alternative economic uncertainty proxies as the third variable of the VAR ordering (in the place of MU as shown in Equation (3)).

[Insert Table 2 Here]

From Table 2, we can observe that almost all proxies of economic uncertainty Granger cause the realized variance of the commodity price index (COMRV). More specifically, the financial uncertainty (FU), the macroeconomic uncertainty (MU) and the economic policy uncertainty (EPU) (and its main components) Granger cause the volatility of the commodity price index. In addition, the causality tests reveal a bidirectional causal relationship between commodity market volatility and the JLN macroeconomic uncertainty (MU) measure. The changes in the RV of commodity price index cause changes in MU. Conversely, as Panel C of Table 2 indicates, while the volatility in the S\&P 500 index and the financial regulation uncertainty (FRU) index have a causal effect on commodity market volatility, we fail to reject the hypothesis of no causality when conducting the test between the logarithm of the VXO index and the realized variance of the commodity market index (COMRV).

\footnotetext{
${ }^{13}$ We additionally run the VAR(3) model to compare the results with the VAR(3) model of Baker et al. (2016). When estimated a VAR model with 3 instead of 4 lags, the main results and conclusions remain unaltered. The estimated IRFs for the VAR(3) model are provided upon request.
} 
The empirical analysis continues by measuring the impact of uncertainty shocks on the volatility of commodity prices. The impact of uncertainty shocks is quantified by estimating the Impulse Response Functions of the multivariate VAR model presented in Equation (3). More specifically, we base our analysis on the estimated IRFs between the logarithm of the various uncertainty indices and the realized variance of the commodity futures price index (COMRV). We firstly estimate the 6factor VAR in which we use the unobserved proxy for macroeconomic uncertainty, i.e., the MU measure. The estimated Impulse Response Functions (IRFs) between macroeconomic uncertainty (MU) and the realized variance of the commodity futures price index (COMRV) are given in Figure 3. ${ }^{14}$

\section{[Insert Figure 3 Here]}

The estimated IRFs in Figure 3 show that a one percentage point (1\%) shock in macroeconomic uncertainty (MU) raises the monthly variance of the commodity price index (COMRV) by almost $1.1 \%$ for the first 3 months after the initial shock. The effect is observed to be both positive and statistically significant for almost 15 months after the initial shock of uncertainty. Essentially, we find that an increase in the JLN unobservable MU measure has a tremendous and long-lasting impact on the volatility of commodity prices. ${ }^{15}$ Our results are in sharp contrast with the findings of the relevant literature (for example, Batten et al., 2010), according to which there are no macroeconomic factors influencing the volatility of the commodity price series. Contrary to this, our analysis reveals that the MU factor is a significant determinant of the time-variation in the broad commodity futures price index, and provides evidence for the existence of a common macroeconomic factor for commodity volatility.

\footnotetext{
${ }^{14}$ In our online appendix we report the estimated orthogonalized Impulse Response Functions in which the shocks in the VAR model are orthogonalized using a Cholesky decomposition. According to Pesaran and Shin (1998), the generalized IRFs are invariant to the ordering of the variables in the VAR model, while the OIRFs are highly sensitive to the VAR ordering. For this reason, in our robustness section, we report the estimated OIRFs for different VAR orderings of the endogenous variables including in the VAR system. Following Pesaran and Shin (1998), we do not have to report the results of the estimated reduced form IRFs for different VAR orderings, since these IRFs are VAR ordering invariant. In addition, our results and basic conclusions remain unaltered when we estimate the OIRFs instead of the generalized ones. Koop et al. (1996) and Diebold and Yilmaz (2012) give further empirical support on these findings.

${ }^{15}$ In the next paragraphs, we provide further robustness and empirical support to this finding. We show that the MU shocks have a significant and long-lasting impact on the volatility of individual commodity prices (e.g., metals and agricultural products), and not only on the variance of the broad commodity price index.
} 
When examining the reverse channel of causality, we find that a positive shock in the realized variance (COMRV) of commodity prices reduces macroeconomic uncertainty (MU) in the short to medium run (2 months after the initial commodity volatility shock). The negative effect reaches its maximum 10 months after the initial commodity volatility shock and remains significant (i.e., statistically different from zero according to the bootstrapped 95\% confidence interval) for approximately 25 months after the initial uncertainty shock. The more sluggish response of macroeconomic uncertainty to changes in the volatility of commodity prices is somewhat expected. The economic interpretation of this negative response has its roots in the construction of the unobservable JLN macroeconomic uncertainty index. This index has been estimated as the purely unforecastable component of macroeconomic fluctuations, thus, when a large commodity volatility episode is materialized, the uncertainty (or the degree of unpredictability) in the macroeconomy falls because of the realization of the volatility shock in commodity markets. Our VAR analysis indicates that when a large shock in commodity markets materializes, then a large fraction of the 'foggy' and uncertain state of the future path of the macroeconomy disappears. These are the first empirical findings showing that the increasing volatility in commodity markets has significant bi-directional linkages with the time-varying degree of unpredictability in macroeconomic fluctuations.

Moreover, we estimate the same 6-factor VAR model of Equation (1) with the financial uncertainty (FU) index instead of the macroeconomic uncertainty (MU) index. The financial uncertainty (FU) index (just like the MU index) is an unobservable uncertainty index which measures the degree of unpredictability in financial markets. Figure 4 shows the estimated IRFs between the realized variance (COMRV) in the commodity market index, and the logarithm of the financial uncertainty (FU) index, along with the $95 \%$ bootstrapped confidence intervals.

\section{[Insert Figure 4 Here]}

From Figure 4 we can observe that an innovation in financial uncertainty (FU) results to an instantaneous increase in commodity price volatility. More specifically, a $1 \%$ positive shock in FU results to a persistent increase in commodity market volatility which reaches its maximum $(0.4 \%)$ in the first 5 months after the initial FU shock and remains positive and statistically significant (within the bootstrapped 
confidence interval) for 14 months after the initial shock. Our results, indicate that both the JNL MU and FU shocks have a significant (in terms of magnitude) and longlasting impact in commodity market volatility. Simply put, when the future state of the macroeconomy and the financial system becomes foggy, the price variability in commodity markets increases as a response. Our VAR analysis additionally shows that the MU shocks have a more significant impact on the RV in commodity markets when compared to the respective impact of FU shocks. Thus, uncertainty about macroeconomic conditions seems to be more important factor that drives time variation in commodity market volatility, when compared to financial uncertainty. In addition, Figure 4 shows that the estimated IRFs of FU to commodity RV shocks are statistically insignificant. These empirical findings show that, while macroeconomic uncertainty is significantly reduced after the occurrence of large volatility swings in commodity markets, the financial uncertainty remains unaffected and immune to changes in commodity market turbulence. Unlike the MU index, the FU index does not have a significant response to commodity market volatility shocks. The Granger causality tests in Table 2 lead us to the same conclusion, since we confirm a bidirectional causality between MU and commodity market RV, and unidirectional causality from FU to commodity market RV.

\subsubsection{The Impact of Observable Uncertainty Shocks}

In this section we present the results from the VAR analysis when we use some widely accepted proxies of economic uncertainty which are based on observable variations of macroeconomic and financial indicators. For example, Bloom (2009) proposes the stock-market uncertainty index (VXO) and the volatility of the S\&P 500 price index (SP500RV) as proxies for economic uncertainty. In addition, Baker et al. (2016) construct an economic policy uncertainty index (EPU) which quantifies the economic policy uncertainty and is based on newspaper articles. The analytical methodology for the construction of the EPU index and its respective components (EPU news policy uncertainty index (EPUNEWS), fiscal policy uncertainty index (EPUFISC) and monetary policy uncertainty index (EPUMON)) can be found in Baker et al. (2016). Unlike the JNL MU and FU uncertainty series, the EPU index, the VXO index and the realized variance of the returns of the S\&P 500 index (SP500RV) are observable indicators of economic fluctuations and, according to 
Jurado et al. (2015), may fluctuate for reasons which are uncorrelated with economic uncertainty. Therefore, by estimating the impact of these alternative uncertainty measures, we can empirically examine which type of uncertainty shock matters most for commodity investors. Figure 5 shows the IRFs between the EPU index, as well as its components, and the RV in commodity market index.

[Insert Figure 5 Here]

Both the magnitude and the responses of the realized variance of the commodity price index to EPU shocks are much smaller when compared to the respective response of the commodity price RV to MU shocks that was presented in the previous section (Figure 3). For example, the commodity price index increases by $0.03 \%$ (3 basis points) in response to a positive 1\% EPU shock. This effect is statistically significant only for the first month and vanishes after the second month. In addition, the response of commodity price volatility to the rising uncertainty about economic news (the news component of the economic policy uncertainty index (EPUNEWS)) is of a similar magnitude. These results show that, unlike the stock-market volatility (Antonakakis et al., 2013; Liu and Zhang, 2015; Arouri et al., 2016), the commodity market volatility seems to be relatively immune and less significantly affected by the observed uncertainty measures about future economic policy. Any kind of economic news which reveal a more uncertain economic environment, has a small and transitory impact on the volatility of commodity prices. In addition, the fiscal and the monetary policy components of the uncertainty index, have also a transitory impact on commodity price volatility, which vanishes after the second month of the initial shock.

Furthermore, we estimate the baseline VAR model of Equation (2), in which we utilize some additional proxies of economic uncertainty, which have been proposed in the relevant literature, such as the stock-market volatility of the S\&P 500 index, the VXO implied volatility index and the financial regulation index (FRU). Figure 6 shows the estimated IRFs for the commodity RV-uncertainty pair when we use the RV of the S\&P 500 index, the VXO index and the FRU index as alternative measures of uncertainty in the VAR model. 
The stock-market volatility and financial regulation uncertainty shocks have a positive, but small and transitory impact on commodity price volatility. For example, a one percentage point (100 basis points) shock in the logarithm of the VXO index increase the volatility in commodity prices by nine $(0.09 \%)$ and two $(0.02 \%)$ basis points respectively, with the effect being statistically insignificant. Overall, our results cannot verify the volatility spillovers hypothesis (Arouri et al., 2011; Diebold and Yilmaz, 2012). While for example, Diebold and Yilmaz (2012) find that there are significant volatility spillover effects from equity to commodity markets, our VAR analysis shows that the impact of stock-market volatility is transitory and small.

\subsubsection{The Impact of Uncertainty Shocks on the Volatility of Individual Commodity Markets}

In this section, we conduct a disaggregated VAR analysis in which we measure the impact of uncertainty shocks on the realized variance (COMRV) of individual commodity prices. Instead of measuring the impact on the broad commodity price index, we measure the impact of uncertainty shocks on the volatility of various agricultural, metals and energy commodities. By using this approach, we implicitly examine whether economic uncertainty is a common volatility risk factor, not only for the aggregate, but also for the individual commodity markets. We estimate 14 models of the baseline VAR of Equation (2), in which we use the RV of each one of the 14 individual commodity prices instead of the broad commodity index. We employ the VAR analysis using the MU and FU measures as economic uncertainty proxies, as we have shown in the previous sections that the RV of the commodity price index has an instant and highly persistent response to MU and FU shocks only. ${ }^{16}$ Figure 7 shows the estimated IRFs for the VAR models in which the volatility of the various agricultural commodity prices is used as the endogenous variable and MU as the economic uncertainty measure. ${ }^{17}$

\footnotetext{
${ }^{16}$ For brevity, we do not report the responses of the volatility of commodity prices to EPU and stockmarket volatility shocks like we did in subsection 3.2.2 for the broad commodity price index. The responses to EPU and stock-market volatility shocks of the volatility series of individual commodities are found to be insignificant. These results can be provided upon request.

${ }^{17}$ The VAR analysis, in this section, is employed over the period from January 1988 to December 2016 which is the common sample for the prices of the 14 individual commodities.
} 
[Insert Figure 7 Here]

The estimated responses of the volatility of agricultural products on the MU shocks are all positive and statistically significant. Our VAR analysis shows that an $1 \%$ MU shock results to an approximately $0.2-0.5 \%$ increase in the monthly realized variance (RV) of the agricultural commodity futures markets. This effect is persistently positive and reaches its maximum 2-3 months after the initial shock in all agricultural commodities under consideration. The estimated response of the RV of corn, wheat and sugar prices to a MU shock is more persistent (the effect remains statistically significant for many months after the initial shock). In contrast, the IRFs show that the MU series is relatively immune to volatility shocks of agricultural commodities. The only exceptions are sugar and wheat which have a positive and significant impact on MU. Figure 8 shows the estimated IRFs between macroeconomic uncertainty (MU) and the realized variance in energy commodity markets.

[Insert Figure 8 Here]

The results indicate that the response of volatility of the energy commodity markets is prompt and long lasting when compared with agricultural markets. For example, a $1 \%$ MU shock results to a $2.5 \%$ increase in the volatility of crude oil prices, and to a $2.2 \%$ increase in the volatility of heating oil prices. This effect is statistically significant for 18 months after the initial macroeconomic shock. In addition, a positive shock in the volatility of energy commodity markets reduces macroeconomic uncertainty. These results indicate a bi-directional causal relationship between energy commodity markets and macroeconomic uncertainty. These findings are in line with Hamilton (1983), Ferderer (1996), Hamilton (2003) and Elder and Serletis (2010) according to which oil price and volatility shocks are closely linked with the state of the macroeconomy and are significant indicators of U.S. economic recessions. Finally, Figure 9 shows the estimated IRFs between MU and the commodity in metals commodity markets.

[Insert Figure 9 Here] 
The IRFs from Figure 9 show that the effect of MU shocks in metals markets is again positive and statistically significant. More specifically, our estimated IRFs show that a $1 \%$ positive MU shock results to an almost equal magnitude increase (about $1 \%$ ) on the volatility of the copper, silver and platinum prices, with the effect being statistically significant for about 15 months after the initial MU shock. The effect of MU shocks is slightly lower on the volatility of gold prices. Lastly, the impact of financial uncertainty (FU) shocks to the volatility of individual commodity prices is again significant, but is of a lower magnitude compared to respective impact of $\mathrm{MU}$ shocks. The results of our VAR analysis, in which we use the FU instead of the MU as the endogenous variable in the VAR model for the agricultural, energy and metals markets, can be found in our online Appendix.

\section{Robustness}

In the online Appendix we conduct various robustness checks to supplement our empirical results, following the VAR analysis of the main paper. First, we estimate the Orthogonalized Impulse Response Function (OIRFs) using a Cholesky decomposition instead of the Generalized IRFs that we report in the main empirical section. We observe that our main findings remain unaltered. Furthermore, we report the estimated OIRFs for alternative VAR orderings, following the VAR ordering of Bloom (2009) and Jurado et al. (2015), and we find that our results remain robust. Moreover, motivated by the empirical studies on the significance of exchange rates (Gilbert, 1989; Chen et al., 2010) and crude oil price shocks (Du et al., 2011; Nazlioglu and Soytas, 2012; Shang et al., 2016) for the price and the volatility path of commodities, we additionally control for the U.S. effective exchange rate and the oil price shocks in the VAR model and we show that our main findings remain unaffected. We also report the Granger causality tests between the uncertainty measures and the realized volatility of the individual agricultural, energy and metals prices and find that there is a bi-directional causality between MU and the volatility in energy markets, while there is a unidirectional causality from MU to the volatility of agricultural and metals prices. Lastly, we include the results of the VAR analysis in which we use the FU and the volatility of the individual agricultural, energy and metals prices. The VAR models and Granger causality tests reveal a significant 
impact of FU shocks on the volatility of agricultural, metals and energy futures markets.

\section{Conclusions}

This paper investigates the impact of uncertainty shocks on commodity price volatility. Our results show that macroeconomic uncertainty increases volatility in commodity markets. Our analysis indicates that the rising degree of unpredictability in the macroeconomy, proxied by the latent uncertainty measure of Jurado et al. (2015), has the most significant and persistent impact on the volatility of commodity prices. Conversely, the observable economic uncertainty measures have a rather transitory and less statistically significant impact on the volatility of commodity prices. Furthermore, our VAR analysis is the first to show the existence of common macroeconomic uncertainty factors driving the dynamics of the time-varying volatility in commodity prices. The results suggest that the more unpredictable the future state of the macroeconomy becomes, the more volatile the prices of commodities would be. Commodity market turbulence does not seem to arise because of macroeconomic and/or stock-market fluctuations. On the contrary, according to our findings it is affected by the rising degree of unpredictability of these fluctuations. In addition, macroeconomic uncertainty is significantly lower after the occurrence of volatility episodes in commodity markets. This illustrates that the commodity price volatility shocks represent a large fraction of the uncertainty in the macroeconomy.

One direction for future research would be the empirical examination of the predictive power of economic uncertainty on the volatility of commodity prices. We believe that it would be of interest to examine the predictive information content of macroeconomic uncertainty on commodity price volatility, when compared to the already empirically verified commodity specific predictors (e.g., the inventory level and the option-implied volatility). This information would be useful for commodity investors, producers and trade-policy makers. 


\section{References}

Antonakakis, N., Chatziantoniou, I., and G., Filis (2013). "Dynamic co-movements of stockmarket returns, implied volatility and policy uncertainty." Economics Letters, 120, 87-92.

Anzuini, A., Lombardi, M.J., and P., Pagano (2013). "The impact of monetary policy shocks on commodity prices.” International Journal of Central Banking, 9(3), 125-150.

Arouri, M., Estay, C., Rault, C., and D., Roubaud (2016). "Economic policy uncertainty and stock markets: Long-run evidence from US.” Finance Research Letters, 18, 136-141.

Arouri, M., Jouini, J., and D.K., Nguyen (2011). "Volatility spillovers between oil prices and stock sector returns: implications for portfolio management." Journal of International money and finance, 30(7), 1387-1405.

Baker, S.R., Bloom, N., and S.J., Davis (2016). "Measuring economic policy uncertainty." Quarterly Journal of Economics, 131(4), 1593-1636.

Barndorff-Nielsen, O. E., and Shephard, N. (2002). "Econometric analysis of realized volatility and its use in estimating stochastic volatility models." Journal of the Royal Statistical Society: Series B (Statistical Methodology), 64(2), 253-280.

Batten, J.A., Ciner, C., and B.M., Lucey (2010). "The macroeconomic determinants of volatility in precious metals markets." Resources Policy, 35(2), 65-71.

Bekaert, G., Hoerova, M., and M., Lo Duca (2013). "Risk, uncertainty and monetary policy." Journal of Monetary Economics, 60 (7), 771-788.

Bloom, N. (2009). "The impact of uncertainty shocks.” Econometrica, 77(3), 623-685.

Caldara, D., Fuentes-Albero, C., Gilchrist, S., and E., Zakrajsek (2016). "The macroeconomic impact of financial and uncertainty shocks." European Economic Review, 88, 185-207.

Carr, P., and Wu, L. (2009). "Variance risk premiums." The Review of Financial Studies, 22(3), 1311-1341.

Chen, Y.C., Rogoff, K.S., and B., Rossi (2010). "Can exchange rates forecast commodity prices?" Quarterly Journal of Economics, 125(3), 1145-1194.

Christensen, B.J., and N.R., Prabhala (1998). "The relation between implied and realized volatility." Journal of Financial Economics, 50(2), 125-150.

Colombo, V. (2013). "Economic policy uncertainty in the US: Does it matter for the Euro area?" Economics Letters, 121, 39-42.

Diebold, F.X., and K., Yilmaz (2012). "Better to give than to receive: Predictive directional measurement of volatility spillovers." International Journal of Forecasting, 28(1), 57-66.

Du, X., Cindy, L. Y., and D.J., Hayes (2011). "Speculation and volatility spillover in the crude oil and agricultural commodity markets: A Bayesian analysis." Energy Economics, 33(3), 497-503. 
Elder, J. (2018). "Oil price volatility: Industrial production and special aggregates." Macroeconomic Dynamics, 22(3), 640-653.

Elder, J., and A., Serletis (2010). "Oil price uncertainty." Journal of Money, Credit and Banking, 42(6), 1137-1159.

Ferderer, J.P. (1996). "Oil price volatility and the macroeconomy." Journal of Macroeconomics, 18(1), 1-26.

Frankel, J.A. (2008). "The effect of monetary policy on real commodity prices." In J.Y. Campbell: Asset Prices and Monetary Policy, University of Chicago Press, pp. 291-333.

Frankel, J.A. (2013). "Effects of speculation and interest rates in a 'carry trade' model of commodity prices." Written for Understanding International Commodity Price Fluctuations, an International Conference organized by the IMF and Oxford University.

Frankel, J.A., and G.A., Hardouvelis (1985). "Commodity prices, money surprises and Fed credibility." Journal of Money, Credit and Banking, 17 (4), 425-438.

Frankel, J.A., and A.K., Rose (2010). "Determinants of agricultural and mineral commodity prices.” In Inflation in an era of Relative Price Shocks. Reserve Bank of Australia.

Gilbert, C.L. (1989). "The impact of exchange rates and developing country debt on commodity prices.” Economic Journal, 99(397), 773-784.

Gilbert, C.L. (2010). "How to understand high food prices." Journal of Agricultural Economics, 61(2), 398-425.

Gordon, G., and K.G., Rouwenhorst (2006). "Facts and fantasies about commodity futures." Financial Analysts Journal, 62, 47-68.

Gubler, M., and M.S., Hertweck (2013). "Commodity price shocks and the business cycle: Structural evidence from the US." Journal of International Money and Finance, 37, 324-352. Hamilton, J. D. (1983). “Oil and the macroeconomy since World War II.” Journal of Political Economy, 91(2), 228-248.

Hamilton, J. D. (2003). "What is an oil shock?” Journal of Econometrics, 113(2), 363-398.

Hammoudeh, S., Nguyen, D.K., and R.M., Sousa (2015). "US monetary policy and sectoral commodity prices." Journal of International Money and Finance, 57, 61-85.

Hammoudeh, S., and Yuan, Y. (2008). "Metal volatility in presence of oil and interest rate shocks." Energy Economics, 30(2), 606-620.

Henzel, S.R., and M., Rengel (2017). "Dimensions of macroeconomic uncertainty: A common factor analysis.” Economic Inquiry, 55(2), 843-877.

Jo, S. (2014). "The effects of oil price uncertainty on global real economic activity." Journal of Money, Credit and Banking, 46(6), 1113-1135.

Joets, M., Mignon, V., and T., Razafindrabe (2016). "Does the volatility of commodity prices reflect macroeconomic uncertainty?" Working paper 607, Banque de France. 
Jurado, K., Ludvigson, S.C., and S., Ng (2015). "Measuring uncertainty." American Economic Review, 105(3), 1177-1216.

Kang, W., and R.A., Ratti (2014). "Oil shocks, policy uncertainty and stock-market returns." Journal of International Financial Markets, Institutions and Money, 26, 305-318.

Kelly, B., Pastor, L., and P., Veronesi (2016). "The price of political uncertainty: Theory and evidence from the option market." Journal of Finance, 71(5), 2417-2480.

Kilian, L. (2008). "Exogenous oil supply shocks: How big are they and how much do they matter for the US economy?" Review of Economics and Statistics, 90(2), 216-240.

Koop, G., Pesaran, M.H, and S.M., Potter (1996). "Impulse response analysis in non-linear multivariate VAR models." Journal of Econometrics, 74(1), 119-147.

Liu, L., and T., Zhang (2015). "Economic policy uncertainty and stock market volatility." Finance Research Letters, 15, 99-105.

Meinen, P., and O., Roehe (2017). "On measuring uncertainty and its impact on investment:

Cross-country evidence for the euro area." European Economic Review, 92, 161-179.

Nazlioglu, S., and U., Soytas (2012). "Oil price, agricultural commodity prices, and the dollar: A panel cointegration and causality analysis." Energy Economics, 34(4), 1098-1104.

Pastor, L., and P., Veronesi (2012). "Uncertainty about government policy and stock prices." Journal of Finance, 67(4), 1219-1264.

Pastor, L., and P., Veronesi (2013). "Political uncertainty and risk premia." Journal of Financial Economics, 110 (3), 520-545.

Pesaran, H.H., and Y., Shin (1998). "Generalized impulse response analysis in linear multivariate models." Economics Letters, 58(1), 17-29.

Pindyck, R.S., and J.J., Rotemberg (1990). "Excess co-movement of commodity prices." Economic Journal, 100, 1173-1189.

Rahman, S., and A., Serletis (2011). "The asymmetric effects of oil price shocks." Macroeconomic Dynamics, 15(S3), 437-471.

Shang, H., Yuan, P., and L., Huang (2016). "Macroeconomic factors and the cross-section of commodity futures returns." International Review of Economics and Finance, 45, 316-332.

Van Robays, I. (2016). "Macroeconomic uncertainty and oil price volatility." Oxford Bulletin of Economics and Statistics, 78(5), 671-693.

Wang, Z., Fausti, S.W., and B.A., Qasmi (2012). "Variance risk premiums and predictive power of alternative forward variances in the corn market." Journal of Futures Markets, 32(6), 587-608.

Watugala, S.W. (2015). "Economic uncertainty and commodity futures volatility." Working Paper No. 15-14, Office of Financial Research. 


\section{Tables}

Table 1: Descriptive Statistics and Unit Root Tests

The table shows the descriptive statistics along with unit root tests (the Augmented Dickey-Fuller test with lag-length based on Schwarz information criterion with a maximum of 12 lags and the Philips-Perron test with Newey-West automatic lag-length). EPU stands for the logarithm of the Economic Policy Uncertainty index of Baker et al. (2016). The EPUNEWS, EPUMON, EPUFISC and FRU series are the respective components of the EPU index representing the uncertainty about macroeconomic news, monetary policy, fiscal policy and financial regulation respectively. The MU1, MU3 and MU12 and the FU1, FU3 and FU12 series represent the logarithms of the latent JLN macroeconomic and financial uncertainty series which refer to the uncertainty over the 1-month, 3-month and 12-month horizon respectively. VXO is the logarithm of the monthly level of the VXO index, SP500 is the logarithm of the monthly level of the S\&P 500 stock-price index, SP500RV is the monthly realized variance of the daily returns of the S\&P 500 index, TERM is the difference between the constant maturity 10-year U.S. government bond yield and the 3-month U.S. Treasury Bill rate, EXCH is the logarithm of the U.S. Effective exchange rate, and COMRV is the realized variance of the daily returns of the S\&P GSCI commodity futures price index. Lastly, MEMP and MIPI are the monthly levels of Industrial production and employment respectively, while OILP is the logarithm of oil price. The data have monthly frequency and cover the period from January 1985 until December 2016.

\begin{tabular}{|c|c|c|c|c|c|c|c|c|c|c|}
\hline & Mean & Std. Dev. & Minimum & Maximum & Skewness & Kurtosis & $\begin{array}{l}\text { ADF test } \\
\text { (level) }\end{array}$ & $\begin{array}{c}\text { ADF test } \\
\text { (differences) }\end{array}$ & $\begin{array}{l}\text { PP test } \\
\text { (level) }\end{array}$ & $\begin{array}{c}\text { PP test } \\
\text { (differences) }\end{array}$ \\
\hline EPU & 4.639 & 0.282 & 4.047 & 5.502 & 0.320 & 2.544 & $-3.532 * * *$ & & $-5.617 * * *$ & \\
\hline EPUNEWS & 4.636 & 0.334 & 3.802 & 5.648 & 0.405 & 3.101 & $-8.000 * * *$ & & $-7.744 * * *$ & \\
\hline EPUMON & 4.384 & 0.577 & 2.808 & 6.011 & 0.054 & 2.730 & $-10.026 * * *$ & & $-10.043 * * *$ & \\
\hline EPUFISC & 4.478 & 0.565 & 3.138 & 5.925 & 0.298 & 2.454 & $-6.615^{* * *}$ & & $-6.559 * * *$ & \\
\hline FRU & 4.198 & 0.973 & 1.777 & 6.777 & -0.033 & 2.879 & $-3.244 * *$ & & $-9.562 * * *$ & \\
\hline MU1 & 4.165 & 0.105 & 4.019 & 4.644 & 1.709 & 7.687 & $-3.549 * * *$ & & $-2.784 *$ & \\
\hline MU3 (MU) & 4.356 & 0.089 & 4.231 & 4.772 & 1.778 & 8.219 & $-3.066^{* *}$ & & $-2.718^{*}$ & \\
\hline MU12 & 4.513 & 0.046 & 4.448 & 4.728 & 1.805 & 8.363 & $-2.995 * *$ & & $-2.687 *$ & \\
\hline FU1 & 4.482 & 0.187 & 4.162 & 5.037 & 0.496 & 2.563 & $-3.297 * *$ & & $-2.808^{*}$ & \\
\hline FU3 (FU) & 4.534 & 0.145 & 4.290 & 4.958 & 0.485 & 2.506 & $-3.261 * *$ & & $-2.759^{*}$ & \\
\hline FU12 & 4.587 & 0.052 & 4.505 & 4.731 & 0.455 & 2.305 & $-3.086 * *$ & & $-2.578^{*}$ & \\
\hline VXO & 2.948 & 0.352 & 2.332 & 4.181 & 0.605 & 3.270 & $-4.281 * * *$ & & $-3.917 * * *$ & \\
\hline SP500RV & 0.032 & 0.066 & 0.002 & 0.828 & 8.131 & 84.414 & $-11.737 * * *$ & & $-12.120 * * *$ & \\
\hline COMRV & 0.041 & 0.050 & 0.003 & 0.497 & 4.511 & 31.326 & $-5.153^{* * *}$ & & $-11.047 * * *$ & \\
\hline TERM & 0.019 & 0.011 & -0.005 & 0.038 & -0.247 & 2.059 & $-3.372 * *$ & & $-3.209 * *$ & \\
\hline SP500 & 6.683 & 0.688 & 5.191 & 7.714 & -0.534 & 2.026 & -1.619 & $-18.346 * * *$ & -1.609 & $-18.341 * * *$ \\
\hline MEMP & 9.625 & 0.158 & 9.346 & 9.801 & -0.497 & 1.634 & -0.900 & $-3.569 * * *$ & -0.357 & $-7.467 * * *$ \\
\hline MIPI & 4.429 & 0.220 & 3.999 & 4.701 & -0.593 & 1.783 & -1.795 & $-5.789 * * *$ & -1.822 & $-17.572 * * *$ \\
\hline $\mathrm{EXCH}$ & 4.489 & 0.137 & 4.235 & 4.969 & 0.647 & 3.953 & $-3.671 * * *$ & & $-3.232 * *$ & \\
\hline OILP & 3.523 & 0.658 & 2.423 & 4.897 & 0.429 & 1.806 & -1.716 & $-14.243 * * *$ & -1.597 & $-13.743 * * *$ \\
\hline
\end{tabular}


Table 2: Granger Causality Tests

The table shows the results of the Granger causality tests between the various economic uncertainty measures and the commodity market uncertainty. The tests refer to the multivariate 6-factor VAR model with 4 lags with the following VAR ordering: [MIPI MEMP $\log$ (Uncertainty) TERM SP500 COMRV]. The Uncertainty index is the variable which represents our proxy for economic uncertainty. The null hypothesis is that the independent variable does not Granger cause the dependent variable. With $*, * *$ and $* * *$ we denote the rejection of the null hypothesis of no causality at the $10 \%, 5 \%$ and $1 \%$ level respectively. Panels A, B and C show the estimated results for the Granger causality tests when we use alternative proxies for economic uncertainty. The time series sample covers the period from January 1985 until December 2016.

Panel A: Unobservable Economic Uncertainty

\begin{tabular}{llcc}
\hline Dependent variable & Independent variable & chi-square & p-value \\
\hline COMRV & MU & $35.78^{* * *}$ & 0.000 \\
COMRV & FU & $11.03^{* *}$ & 0.026 \\
MU & COMRV & $16.48^{* * *}$ & 0.002 \\
FU & COMRV & 3.00 & 0.56 \\
\hline
\end{tabular}

Panel B: Observable Economic Policy Uncertainty

\begin{tabular}{llcc}
\hline Dependent variable & Independent variable & chi-square & p-value \\
\hline COMRV & EPU & $8.23^{*}$ & 0.083 \\
COMRV & EPUNEWS & $10.13^{* *}$ & 0.038 \\
COMRV & EPUMON & $7.77^{*}$ & 0.100 \\
COMRV & EPUFISC & $11.99 * *$ & 0.017 \\
EPU & COMRV & 7.12 & 0.127 \\
EPUNEWS & COMRV & $9.92^{* *}$ & 0.042 \\
EPUMON & COMRV & 4.34 & 0.362 \\
EPUFISC & COMRV & 4.70 & 0.319 \\
\hline
\end{tabular}

Panel C: Additional Observable Proxies for Economic Uncertainty

\begin{tabular}{llcc}
\hline Dependent variable & Independent variable & chi-square & p-value \\
\hline COMRV & FRU & $9.49^{* *}$ & 0.050 \\
COMRV & VXO & 1.279 & 0.865 \\
COMRV & SP500RV & $8.69^{*}$ & 0.069 \\
FRU & COMRV & 1.57 & 0.814 \\
VXO & COMRV & 4.60 & 0.330 \\
SP500RV & COMRV & 1.24 & 0.871 \\
\hline
\end{tabular}




\section{Figures}

Figure 1: Commodity Market Volatility and Macroeconomic Uncertainty

The figure shows the contemporaneous time series movements between Macroeconomic Uncertainty (MU) and the Realized Variance of the Commodity Price Index (COMRV).

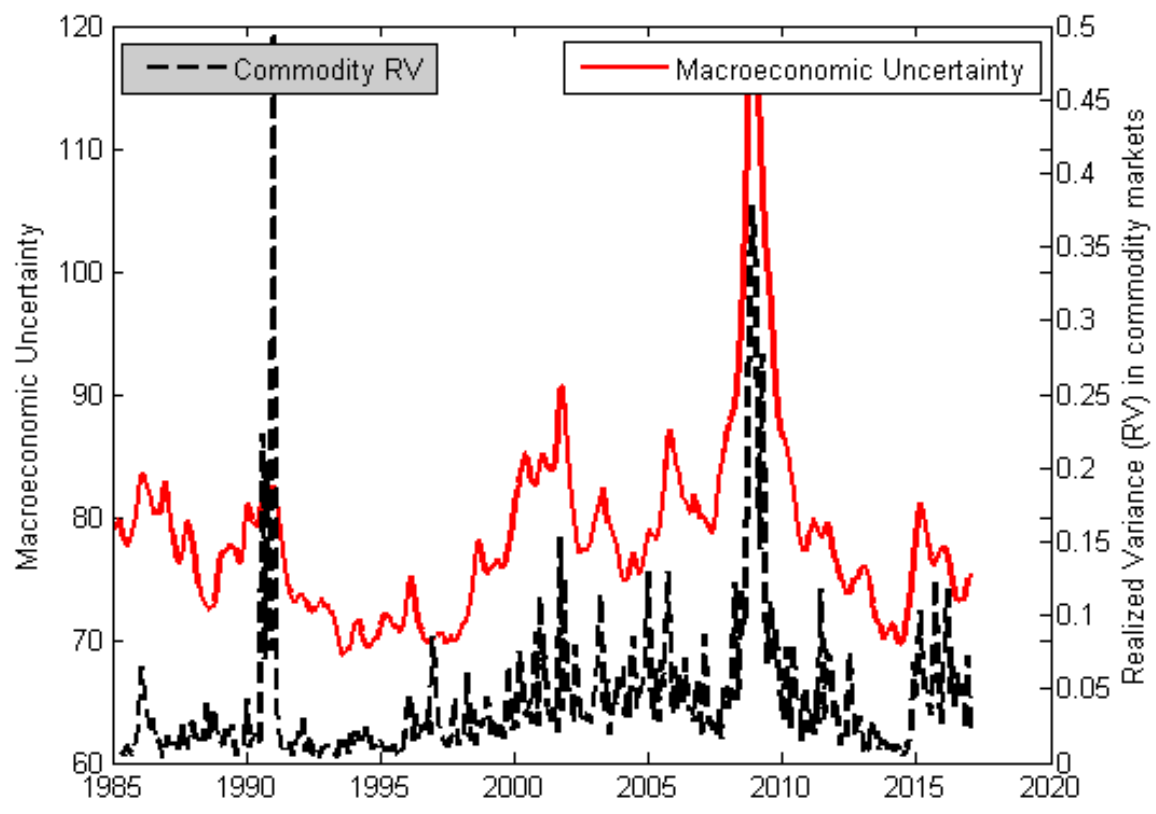

Figure 2: Commodity Market Volatility and Financial Uncertainty

The figure shows the contemporaneous time series movements between Financial Uncertainty (FU) and the Realized Variance of the Commodity Price Index (COMRV).

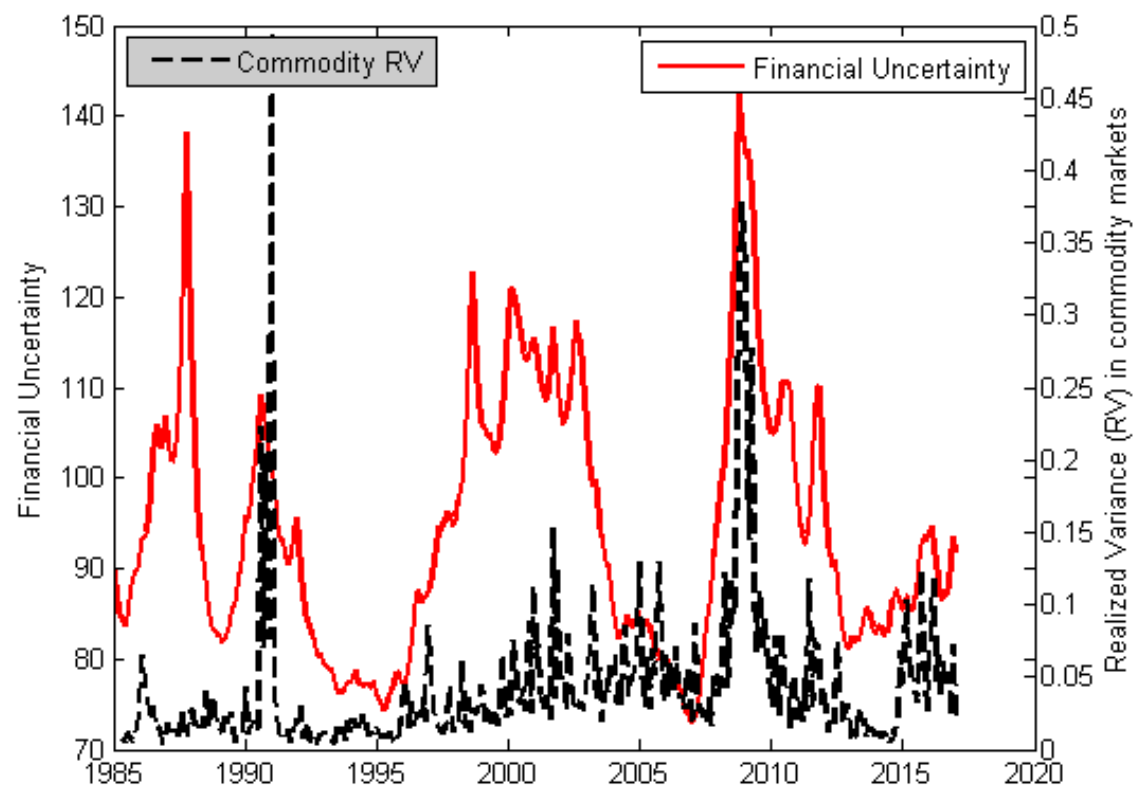


Figure 3: Impulse Response Functions (IRFs) between Commodity Market Volatility and Macroeconomic Uncertainty

The figure shows the estimated IRFs between Macroeconomic Uncertainty (MU) and the Realized Variance of the Commodity Futures Market Index (COMRV). The estimated responses are derived from the baseline 6-factor VAR model of Equation (2) and (3). The blue line shows the estimated IRFs and the dashed lines show the corresponding $95 \%$ bootstrapped confidence intervals. The bootstrapped standard errors have been estimated using 1000 replications.
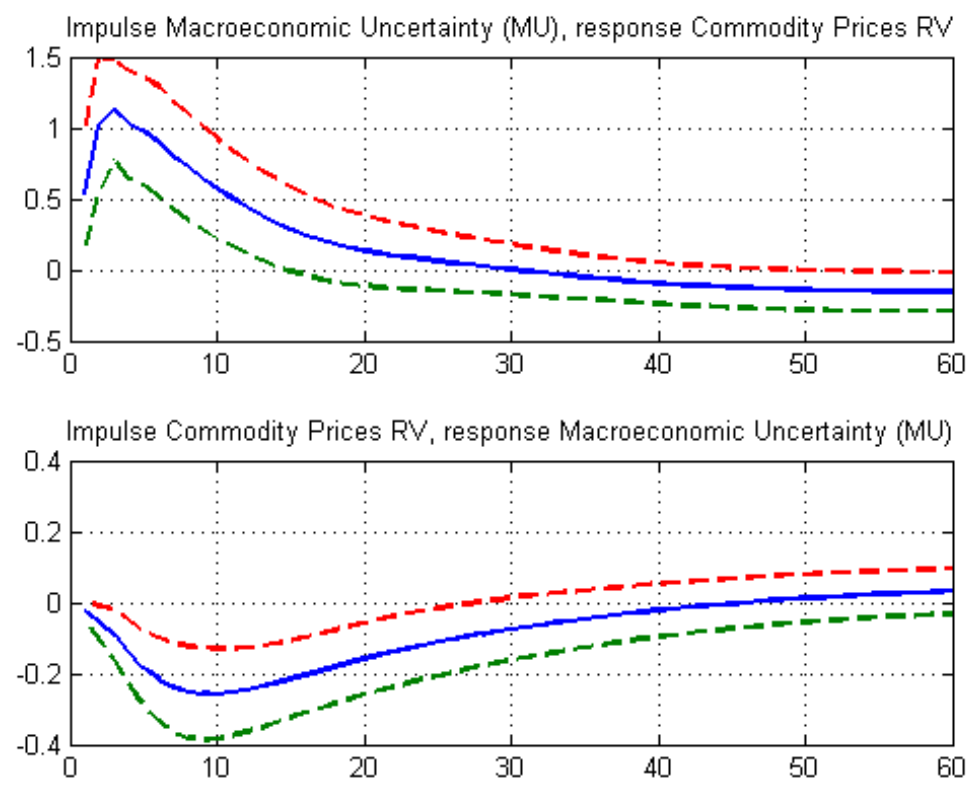

Figure 4: Impulse Response Functions (IRFs) between Commodity Market Volatility and Financial Uncertainty

The figure shows the estimated IRFs between Financial Uncertainty (FU) and the Realized Variance of the Commodity Futures Market Index (COMRV). The estimated responses are derived from the baseline 6-factor VAR model of Equation (2) and (3). The blue line shows the estimated IRFs and the dashed lines show the corresponding $95 \%$ bootstrapped confidence intervals. The bootstrapped standard errors have been estimated using 1000 replications.
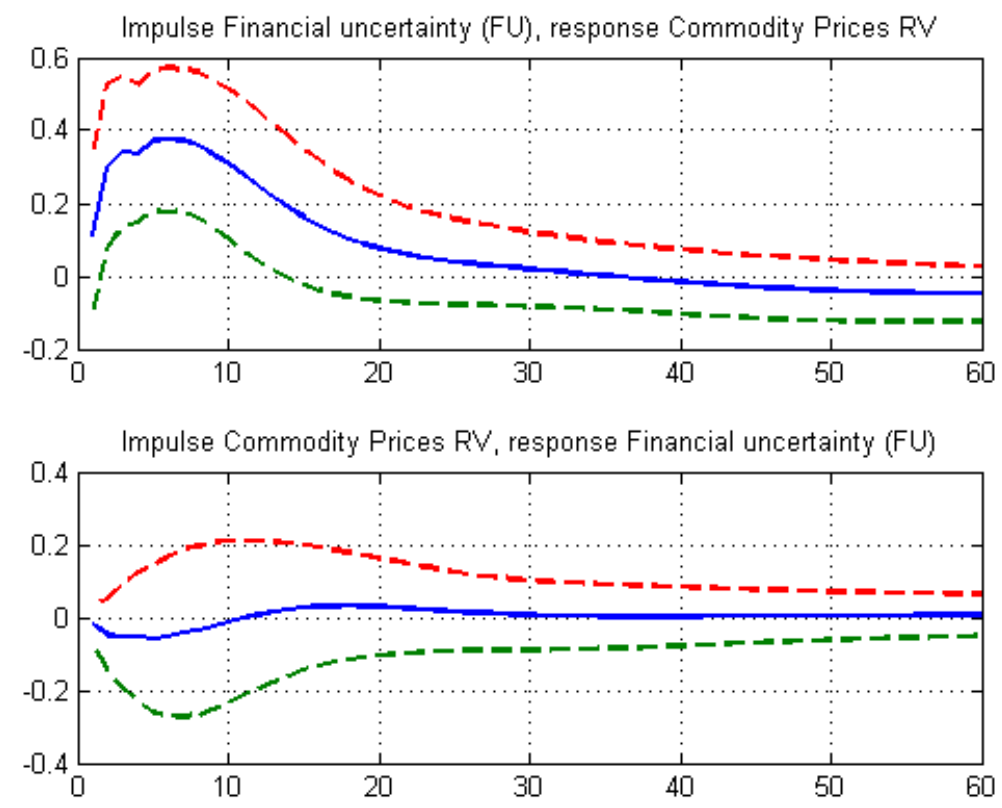
Figure 5: Impulse Response Functions (IRFs) between Commodity Market Volatility and Various Proxies of Economic Policy Uncertainty

The figure shows the estimated IRFs between the various measures of economic policy uncertainty and the Realized Variance of the commodity futures price index (COMRV). The estimated responses are derived from the baseline 6-factor VAR model of Equation (2) and (3). Panel A shows the responses of Commodity Market Volatility shocks to Policy Uncertainty and Panel B shows the responses of Policy Uncertainty to Commodity Volatility shocks.

\section{Panel A}

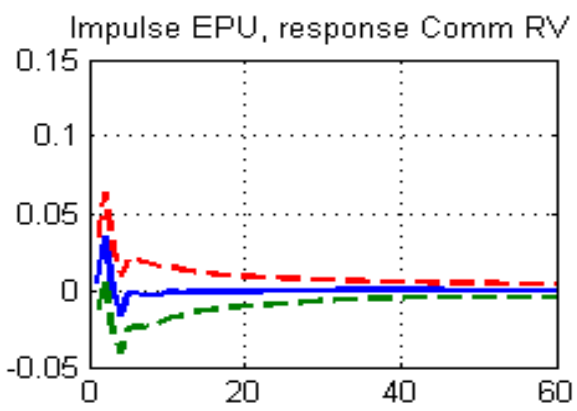

Impulse EPUNews, response Comm RV

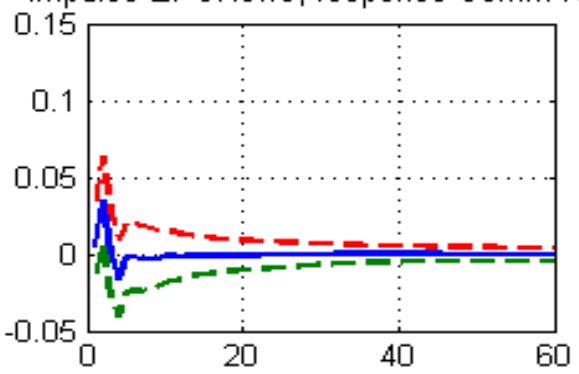

Impulse Fiscal, response Comm RV

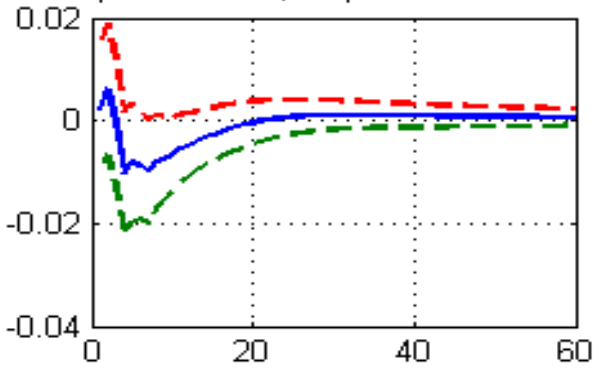

Impulse Monet, response Comm RV

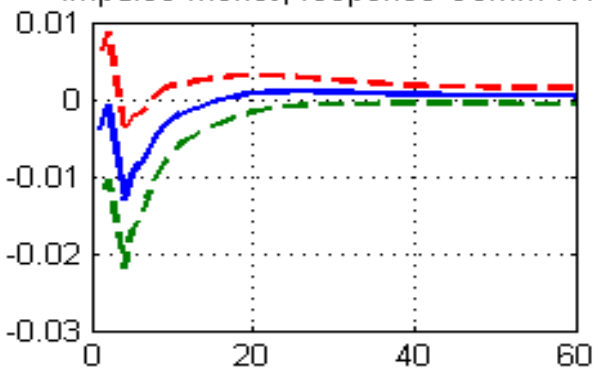

Panel B

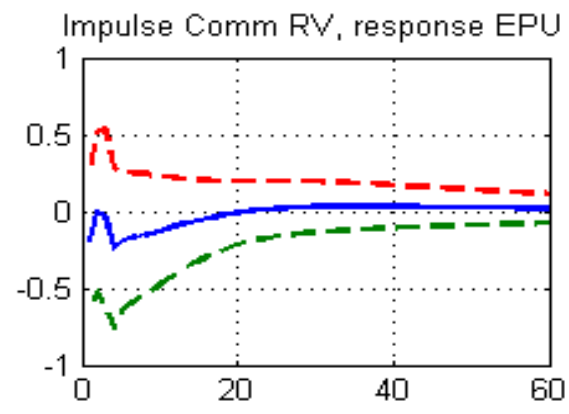

Impulse Comm RV, response EPUNews

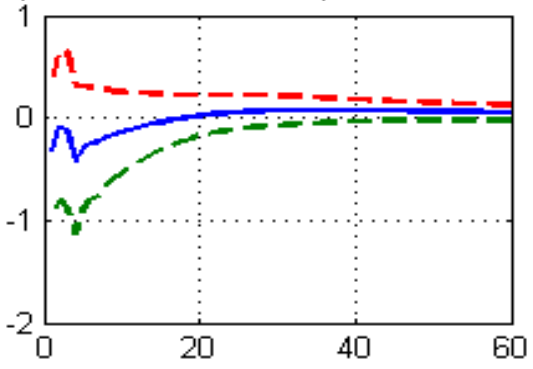

Impulse Comm RV, response Fiscal

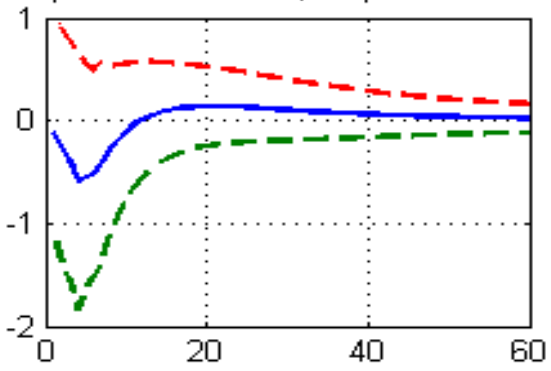

Impulse Comm RV, response Monet

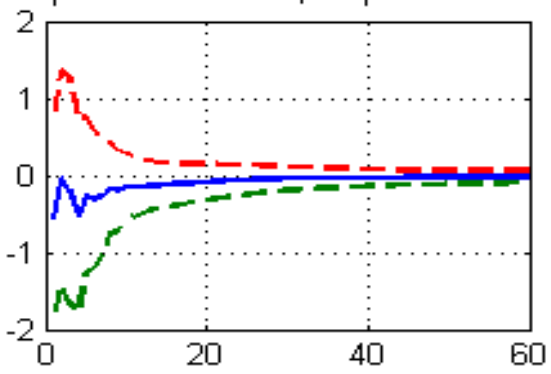


Figure 6: Impulse Response Functions (IRFs) between Commodity Market Uncertainty and Various Proxies of Financial Uncertainty

The figure shows the estimated IRFs between the various financial uncertainty measures and the Realized Variance of the commodity futures price index (COMRV). The estimated responses are derived from the baseline 6-factor VAR model of Equation (2) and (3). FRU stands for the logarithm of the Financial Regulation Uncertainty, SP500RV is the monthly realized variance of daily returns of the S\&P 500 stock-market index, and VXO is the logarithm of the VXO index. Panel A shows the responses of COMRV to a shock in the logarithm of FRU, SP500RV and VXO series, respectively, while Panel B shows the responses of the logarithm of FRU, SP500RV and VXO to a shock in COMRV.

Panel A

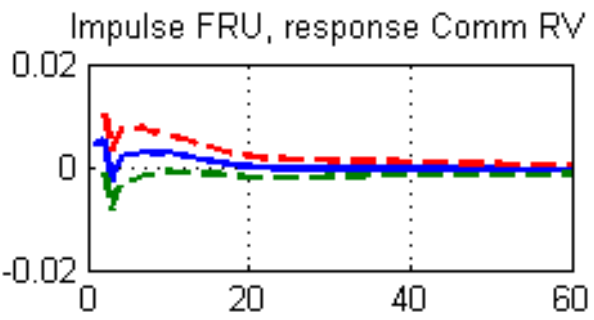

Impulse SP500RV, response Comm RV

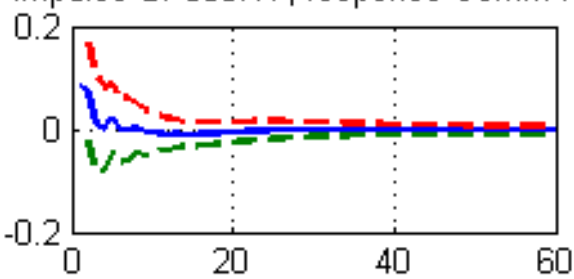

Impulse $\mathrm{VXO}$, response Comm RV

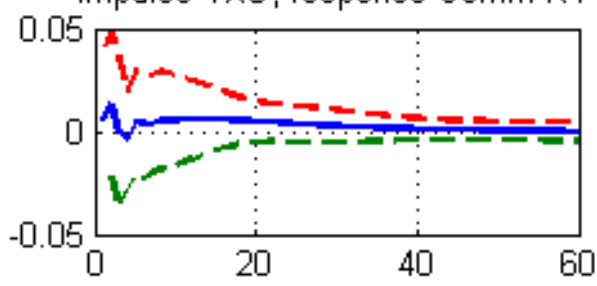

Panel B

Impulse Comm RV, response FRU

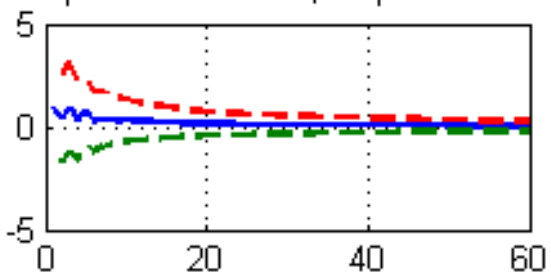

Impulse Comm RV, response SP500RV

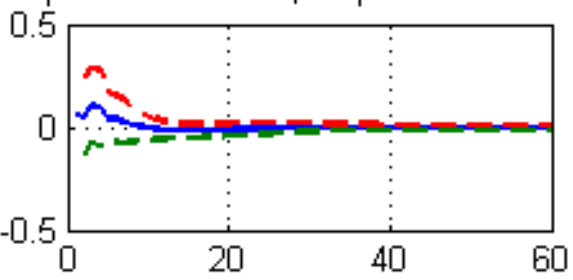

Impulse Comm RV, response $\mathrm{VXO}$

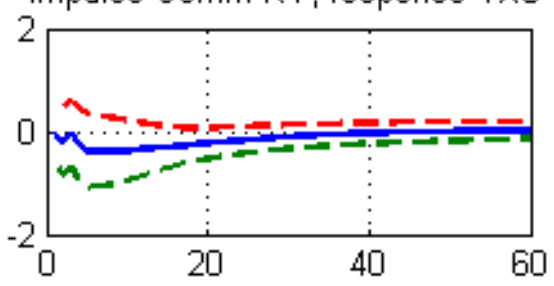


Figure 7: Impulse Response Functions (IRFs) between Realized Variance of Agricultural Commodity Markets and Macroeconomic Uncertainty

The figure shows the estimated IRFs between macroeconomic uncertainty (MU) and the Realized Variance (RV) of the agricultural commodity markets (cocoa, corn, cotton, soybeans, sugar, wheat). The estimated responses are derived from a baseline 6-factor VAR model provided in Equation (2) and (3). Panel A shows the responses of Agricultural Commodity Market Volatility to Macroeconomic Uncertainty shocks and Panel B shows the responses of Macroeconomic Uncertainty to Agricultural Commodity Volatility shocks.

Panel A

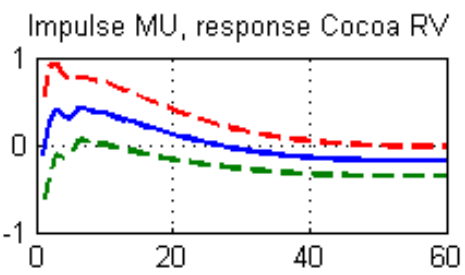

Impulse MU, response Corn RV

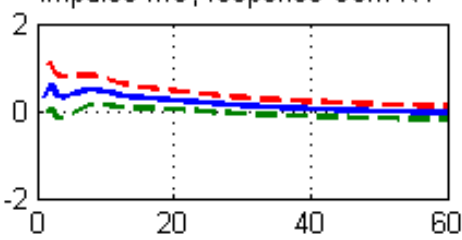

Impulse $\mathrm{MU}$, response Cotton RV

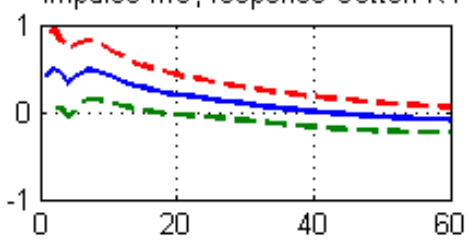

Impulse MU, response Soybeans RV

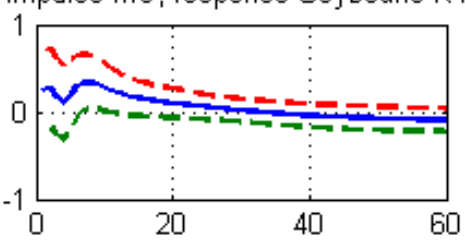

Impulse MU, response Sugar RV

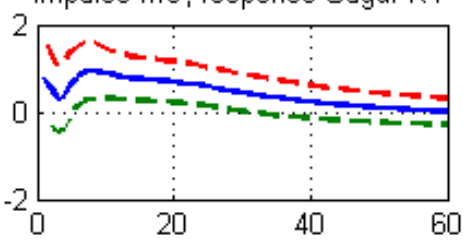

Impulse $\mathrm{MU}$, response Wheat RV

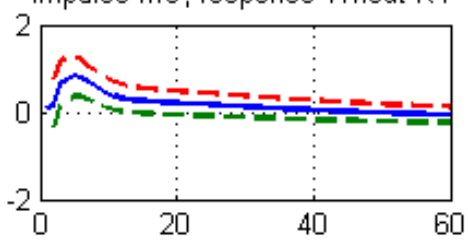

Panel B

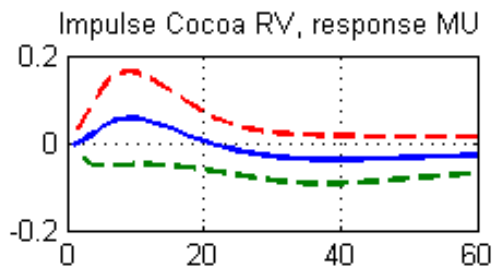

Impulse Corn RV, response MU

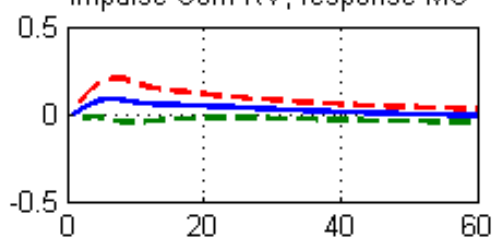

Impulse Cotton RV, response MU

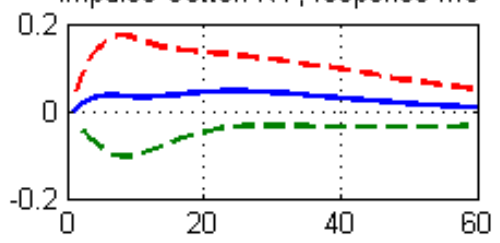

Impulse Soybeans RV, response MU

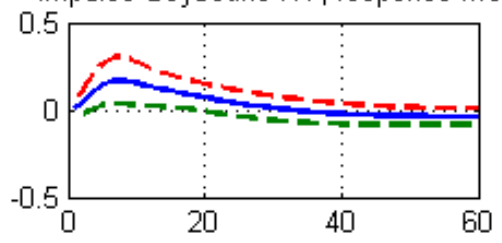

Impulse Sugar RV, response MU

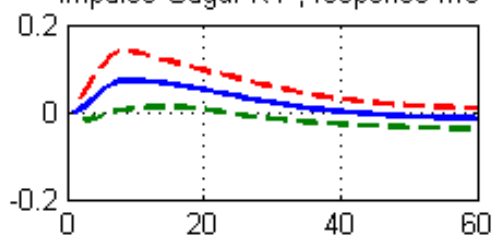

Impulse Wheat RV, response MU

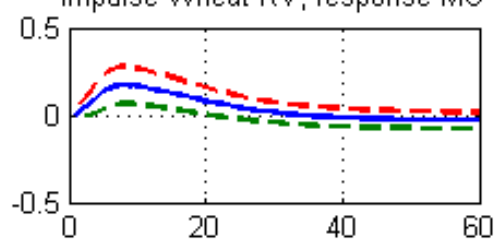


Figure 8: Impulse Response Functions (IRFs) between Realized Variance in Energy Commodity Markets and Macroeconomic Uncertainty

The figure shows the estimated IRFs between macroeconomic uncertainty (MU) and the Realized Variance (RV) of the energy commodity markets (crude oil, heating oil, petroleum and unleaded gasoline). The estimated responses are derived from a baseline 6-factor VAR model provided in Equation (2) and (3). Panel A shows the responses of Energy Commodity Market Volatility to Macroeconomic Uncertainty shocks and Panel B shows the responses of Macroeconomic Uncertainty to Energy Commodity Volatility shocks.

Panel A

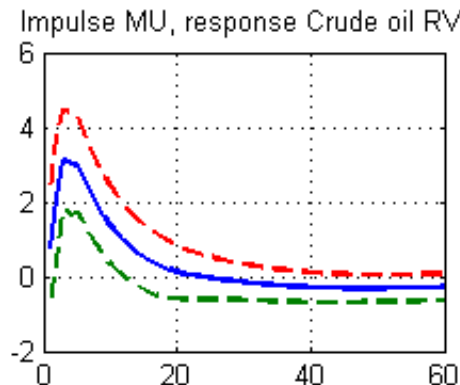

Impulse MU, response Heat oil RV

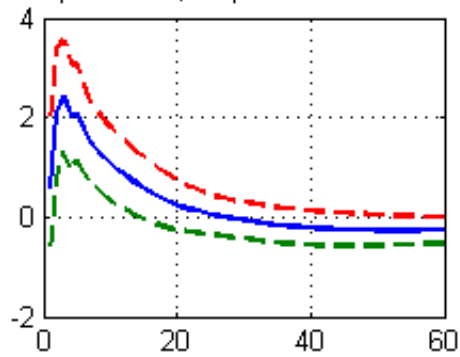

Impulse MU, response Petroleum RV

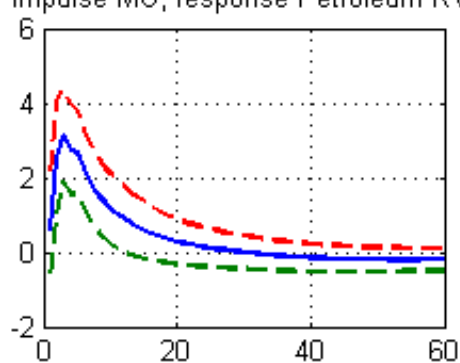

Impulse $\mathrm{MU}$, response Unl gas RV

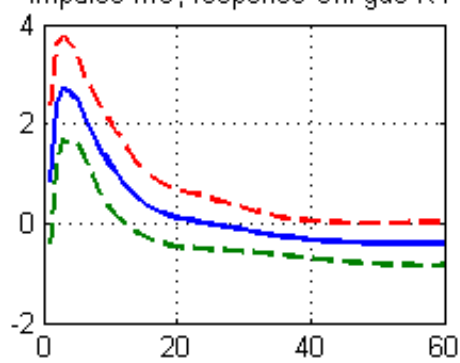

\section{Panel B}
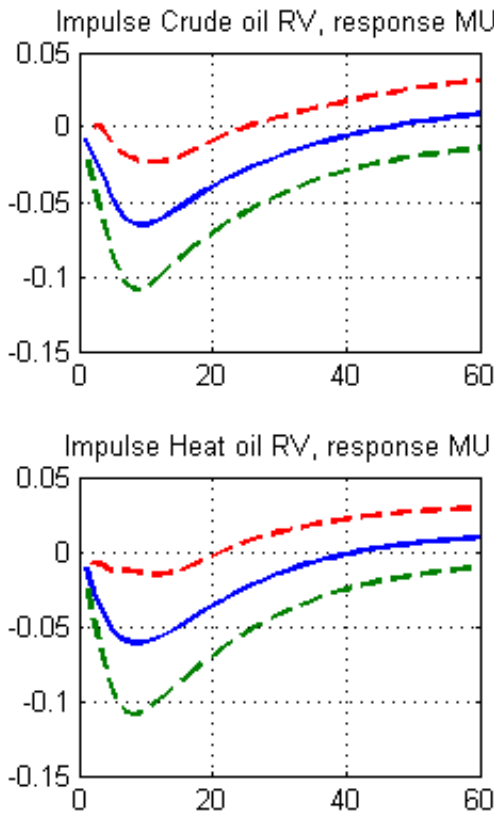

Impulse Petroleum RV, response MU

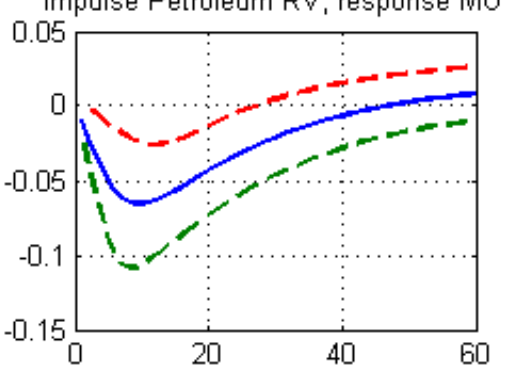

Impulse Unl gas RV, response $\mathrm{MU}$

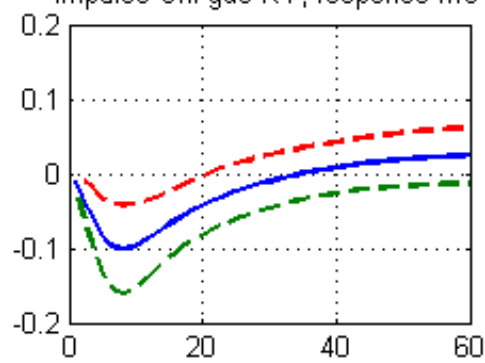


Figure 9: Impulse Response Functions (IRFs) between Realized Variance in Metals Commodity Markets and Macroeconomic Uncertainty

The figure shows the estimated IRFs between macroeconomic uncertainty (MU) and the Realized Variance (RV) in the metals commodity markets (gold, silver, copper and platinum). The estimated responses are derived from the baseline 6-factor VAR model provided in Equation (2) and (3). Panel A shows the responses of Metals Commodity Market Volatility to Macroeconomic Uncertainty Shocks and Panel B shows the responses of Macroeconomic Uncertainty to Metals Commodity Market Volatility shocks.

Panel A
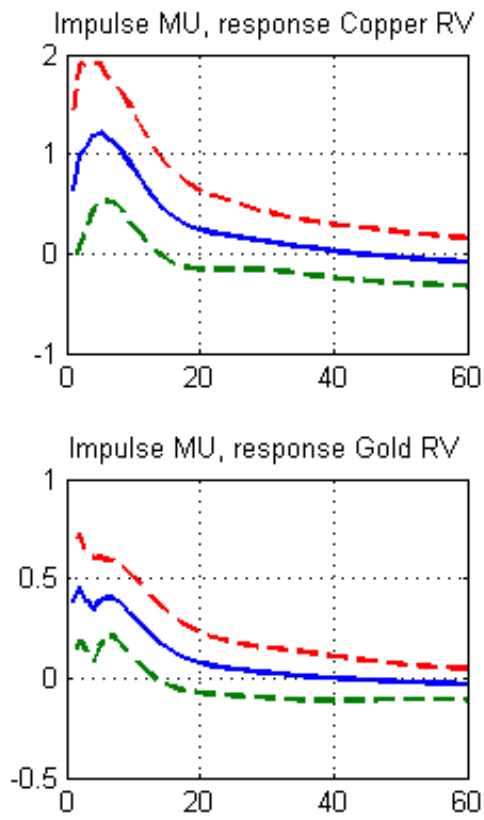

Impulse MU, response Platinum RV

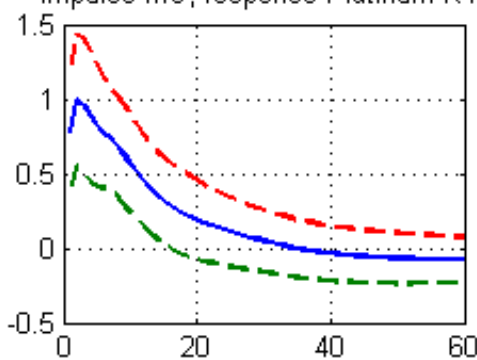

Impulse MU, response Silver RV

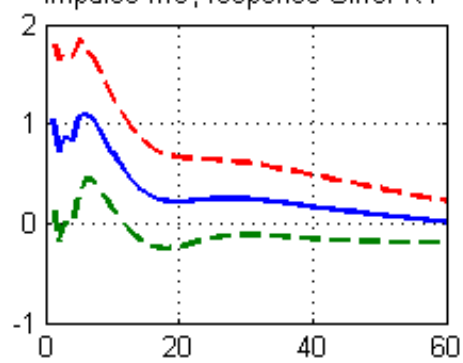

Panel B
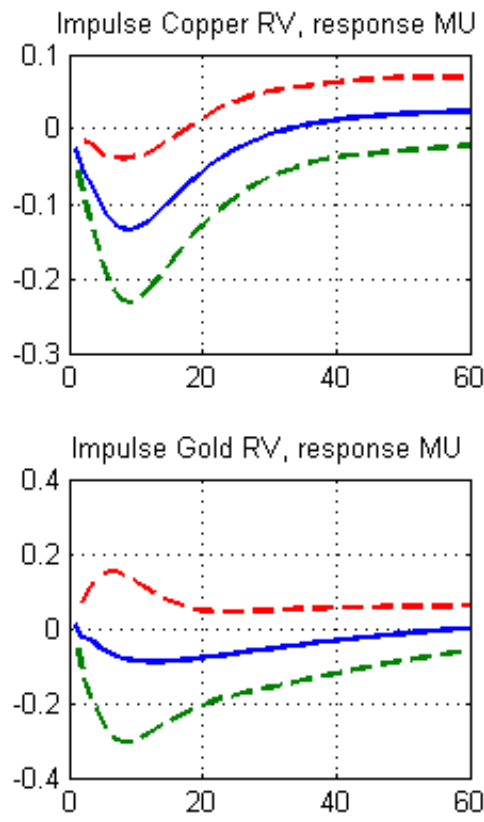

Impulse Platinum RV, response MU

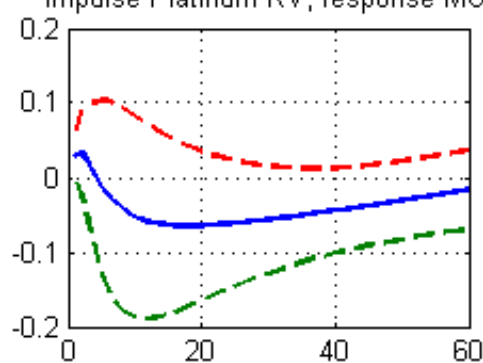

Impulse Silver RV, response MU

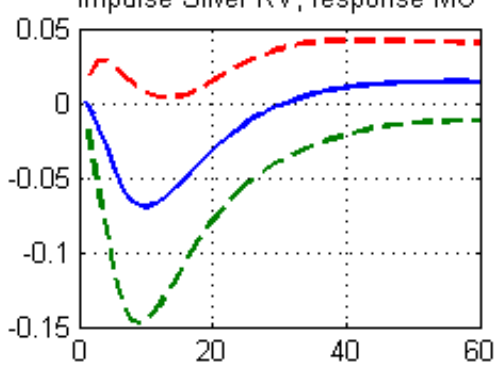

